\title{
Effect Analysis of the Sports Dance Teaching on the Healthy Personality of College Students
}

\author{
Zhang Mengyuan
}

Teacher's College of BeiHua University, Jilin City, China

18254551@qq.com

Keywords: Effect Analysis, Sports Dance Teaching, Healthy Personality, College Students

\begin{abstract}
Sports dance, also known as the international standard dance, is a popular dance by the masses of social life. Because it has a social, entertainment, sports fitness and athletic performances and other social functions, it has a broad mass base. With the popularization of social development and sports dance, sports dance teaching has become an elective course for colleges and universities. Sports dance cannot only improve the quality of students, but also affect the health of college students' personality. Through the discussion of the characteristics of the sports dance project and the connotation of the healthy personality of the college students, the paper analyzes the influence of the sports dance teaching on the healthy personality of college students and explores the methods and ways of cultivating the healthy personality of college students through the teaching of sports dance
\end{abstract}

\section{Introduction}

Sports dance originated in the United Kingdom, that is, men and women as a group, in the accompaniment of dance, with beautiful dance as a form of expression of sports. In this process, the body of the United States, the beauty of personality can be displayed. The process of dancing cannot only strengthen the exchange of feelings between students, but also can shape the body, showing elegant temperament and darling demeanor. The content of sports dance teaching in colleges and universities is mainly the basic theory of dance, the characteristics and rules of dance, the method of competition and the dance teaching of waltz and so on.

With the continuous improvement of socialist modernization, the rapid economic development, more and more intense social competition, employers demand for talent is getting higher and higher. Therefore, it is very important to strengthen the cultivation of college students' comprehensive quality. And sports dance is its unique charm and function in colleges and universities to start, and by the majority of students welcome. Sports dance is a kind of competitive dance culture developed by folk dance and social dance. It is a new type of sports combining sports and art, health and beauty. It integrates entertainment, sports and art. Sports dance in college physical education curriculum, and by college students of the favor, to cultivate college students noble sentiment, exercise perseverance character, enhance college students physical, mental health, the development of sound personality and aesthetic ability to improve have an important role.

\section{The Characteristics of Sports Dance Projects}

Sports dance is a fitness, athletic performance, culture temperament and cultural cultivation of sports, it is in the accompaniment of music, the use of various types of movements, integration of sports, music, dance as one body movement. Sports dance to the movement of the human body as the main means of expression, through the form of action to express ideological and social life, scholars through fast, slow, strong, weak music rhythm to complete the coherent dance movements. In the dance sports dance requirements with the palm, palm with the transition, while the focus of the movement to be coherent, dancers to complete the action to be at one go, compact and coherent, so that dance looks more beautiful. In the whole set of sports dance movements, the most attractive 
is the dance modeling action. In the rhythm of the rhythm of the body, the short yet static posture, enhance the ornamental value of sports dance.

"Sports dance is also known as the international standard ballroom dance, including standard dance (modern dance) and Latin dance two groups, including standard dance (modern dance) contains waltz, Vienna waltz, tango, fox step and fast dance, Latin. The dance includes Rumba, Chamba, Samba, Cowboys and Bullfighting, a sporting event of walking and dancing for men and women. Each dance has its own dance, dance and style, and can be based on different music and action requirements, design and arrangement of different sets of dance movements. "Sports dance in China is an emerging sports project, although the late development, but also in the country has been widely recognized by the community, and some scholars for sports dance related issues were studied.

\section{The Development and Educational Significance of Sports Dance}

Chinese traditional education model in a prominent problem embodied in the accumulation of knowledge, pay attention to the cultivation of professional quality, in the cultivation of students in the perfect personality is inherent deficiencies. With the advent of the era of knowledge economy, the overall development of the people put forward higher requirements, only healthy and perfect personality to adapt to modern society. Therefore, we must first from the intelligence, one-sided emphasis on science and technology education out of the misunderstanding, follow the education reform, to strengthen the quality of education students. Strengthen the quality of education and the ultimate goal is to cultivate the younger generation to become a perfect personality, people's physical and mental development in harmony.

In this context, to take what approach, methods in shaping the personality of college students can produce the greatest performance, or choose what education material to complete the activities of shaping the perfect personality of the most educational value. In this activity, dance is its main content and important way. According to archaeologists, it is proved that dance is the beginning of all civilization. With the development of social productive forces, the content of the dance is richer, thus forming a variety of types of dance. Sports dance is one of them. Since its entry into China in the 1980s, it has been popular with people, especially by college students, has been popular in many colleges and universities. This phenomenon is determined by the unique cultural characteristics of sports dance, it is a financial music, dance, clothing, grace, body beauty in one of the emerging sports. Sports dance both the characteristics of literature and sports, is between the arts and sports between the edge of the project, with a special value of educating people, by contrast, its impressive content is unmatched by other projects. Sukhomlinski said the words: beauty is a spiritual gymnastics and it makes us spirit of integrity, conscience pure, emotional and beliefs correct. From which we can understand that if people long from the aesthetic, will be separated from the psychological development of the balance, harmony and integrity. If this psychological imbalance cannot make up for a long time, it will make people become cold, mechanical, numb, and ultimately lead to personality loss or even collapse.

In this study, it is through the search for the unique value of educating people in the teaching of sports dance. The teaching starts directly from the emotion that affects people, and makes the infection and influence of the students in the United States, so that their spiritual realm can be sublimated, and thus leads to the psychological structure Integrity, balance and harmonious development, so that students gradually achieve the harmony of human nature, and ultimately get a sound, perfect personality.

\section{The Impact of Sports Dance Teaching on the Healthy Personality of College Students}

Personality is social, complex, unique and holistic. Sociality shows that people can be socially affected by the social individual, under the influence of society will have a social imprint, which is unable to disappear out of thin air; complexity shows that people are not single cell animals, people can think can work, Personality can also change with the change of the environment, change with 
the change of the times; the complexity of personality is something that is revealed by human beings and the combination of things that are inherently contained; the uniqueness of personality, different The personality of each person's personality is independent, different personality to highlight the personality of the unique; personality integrity, refers to the personality of the components are not alone, they complement each other to contain each other, acting together on the human personality.

The development of contemporary college students' personality presents a wide variety, the characteristics of the uneven, on the recent occurrence of the Tanggu bombing in Tianjin as an example. Some college students are always concerned about the latest situation of the explosion, so some people come to the affected areas to rescue. There are some students who cannot visit the disaster area for field rescue, but they have been encouraging those victims, and even immediately on the donation activities. But at the same time, there are a lot of college students all day doing nothing, only concerned about the game, entertainment gossip and other trivial matters. It can be seen that the values of contemporary college students is very unstable, personality is also varied. Although the higher education, but in moral awareness and moral behavior still have a certain gap.

Healthy personality needs to have the following conditions: have a sense of self-security; can fully understand themselves, and can make a modest assessment of their ability; life ideal fit; not from the surrounding real environment; to maintain the integrity and harmony of personality ; Good at learning from experience; to maintain good interpersonal relationships; can moderately vent and control emotions; meet the collective requirements under the premise of appropriate play personality; without prejudice to social norms under the premise of being able to properly meet the individual basic needs. Of course, this ten in the sports dance teaching process also reflected most vividly. First of all, in the learning process, we have to maintain a good mental state and adequate self-security cannot think and boys dance will be dangerous, cannot be rejected because of shy. Also, we should be based on their own ability in the teacher's choice to choose the right partner, and dance in the process of dance cannot insist, to meet the norms of dance, on this basis to improve the action or their own characteristics into it, so neither look too selfish but also more perfect performance of their own.

\section{The Approach and Methods of Sports Dance Teaching to Create A Sound Personality}

Cultivate the Aesthetic Quality of College Students. The main task of beauty training is to cultivate the students to feel the beauty, understand the beauty and the ability to create beauty and these are the basic elements of college students' aesthetic quality. Aesthetic training is to let college students directly perceive the beautiful language of action in dance, although these action language comes from daily life, but with the daily life of physical labor and there is a big difference, therefore, teachers in the teaching of the aesthetic The process should focus on the rhythm and attitude of the guidance, to improve their sports dance skills, music, feelings, so that students can personally feel the beauty of the existence. Through the practice of aesthetic training materials, such as tango dance in the dodge action, modern dance and Latin dance dress style, music rhythm fast, slow, strong, weak and their own dance action amplitude, intensity and emotional control, etc. Turn on the emotional pipeline of college students, thus opening their window of mind. In the teaching process, sports dance teachers in addition to guiding students to feel the United States, but also to guide their understanding of the United States, that is, to guide them to understand the aesthetic object of the origin, background, meaning, role, in order to stimulate the creation of students' desire toggle the students' chord, arouse the students' truth.

Cultivate the Innovation Ability of College Students. The cultivation of college students' innovative ability mainly depends on the innovative education of them. In teaching, if we can regard college students as the real subject of aesthetic training, so that they dancing into the situation, because of Wisdom, interpretation of sports dance in some of the uncertain factors, one can fully reflect their own personality to Personal characteristics to enrich the phenomenon of simplification in the work, or to different from the style of others to simplify the work of the complex phenomenon, then, be sure to make innovative wisdom and innovative fun filled with 
sports dance aesthetic training teaching. In short, the sports dance teachers should focus on the characteristics of beauty training in the sports dance, and then follow the aesthetic training path of perception, comprehension and re-perception. To promote students to find the United States, the ability to create beauty to be improved, to achieve the students in the United States experience the sublimation of its aesthetic complex, so as to shape the aesthetic personality, so that all-round development, - to the integrity of college students personality, sound.

Pay Attention to the Cultivation of Honesty of College Students. Honesty is the cornerstone of building a personality building, is an important prerequisite for college students to live and treat life. In the sports dance works appreciation, college students should be devout with the psychological to complete, in order to feel the beauty of appreciation of the works in order to accept this beauty and by the edification to grow. Otherwise the hypocrisy of the works to reduce or exaggerate can cause them to learn, life behavior on the missing and back. In fact, appreciate our life is always there, everywhere, between people accept each other, so that because of appreciation, between people choose to accept or because there is appreciation. The development of honesty should be consistent with the appreciation of teaching always, so that college students in sports dance works to enjoy the lesson, the soul by the United States and the United States deposition, personality also won again and again.

\section{Conclusion}

Sports dance must exist in the existence of the truth and significance, we need to see the positive aspects of its existence, such as to promote emotional exchanges between students, to promote health and enhance self-confidence, to overcome the fear of getting along with people embarrassing and so on. Second, we have the courage to overcome the difficulties to maintain a full sense of security for their own level has a suitable and accurate positioning, positive and optimistic to look at this course. In short, the study of the course for the healthy personality to develop the impact is bound to outweigh the disadvantages.

\section{References}

[1] Hui Zhou: Journal of Hunan University of Science and Technology, Vol. 6 (2012) No 53, p.25-26

[2] Xiao Lin: Journal of Xi'an Institute of Physical Education, Vol. 12 (2015) No 27, p.74-76

[3] Qin Guo: Journal of Jiaxing University, Vol. 1 (2011) No 33, p.11-14

[4] Jieming Liu: Guangxi Normal University, Vol. 3 (2013) No33, p.121-124

[5] Jia Xin. Journal of Wuhan Institute of Physical Education, Vol. 6 (2014) No 53, p.25-26 